\title{
Risk Factor and Pathophysiology of Nephrolithiasis: A Review Article
}

\author{
Nanda Rachmad Putra Gofur ${ }^{1 *}$, Aisyah Rachmadani Putri Gofur ${ }^{2}$, Soesilaningtyas ${ }^{3}$, Rizki Nur Rachman Putra Gofur ${ }^{4}$, Mega Kahdina ${ }^{4}$, \\ Hernalia Martadila Putri ${ }^{4}$, \\ ${ }^{1}$ Department of Health, Faculty of Vocational Studies, Universitas Airlangga, Surabaya, Indonesia. \\ ${ }^{2}$ Faculty of Dental Medicine, Universitas Airlangga, Surabaya, Indonesia. \\ ${ }^{3}$ Department of Dental Nursing, Poltekkes Kemenkes, Surabaya, Indonesia. \\ ${ }^{4}$ Faculty of Medicine, Universitas Airlangga, Surabaya, Indonesia.
}

*Corresponding author: Nanda Rachmad Putra Gofur, Department of Health, Faculty of Vocational Studies, Universitas Airlangga, Surabaya, Indonesia.

Received date: March 01, 2021: Accepted date: April 07, 2021: Published date: April 10, 2021

Citation: N Rachmad Putra G, A Rachmadani Putri G, Soesilaningtyas, Rizki N R P Gofur, M Kahdina, et al. (2021) Risk Factor and Pathophysiology of Nephrolithiasis: A Review Article. Journal of Clinical Surgery and Research. 2(1) DOI: 10.31579/2768-2757/007

Copyright: (92021 Nanda Rachmad Putra Gofur, This is an open-access article distributed under the terms of the Creative Commons Attribution License, which permits unrestricted use, distribution, and reproduction in any medium, provided the original author and source are credited.

\begin{abstract}
:
Introduction: Nephrolithiasis is a urinary tract stone disease that can be found in the kidneys, ureters, bladder, and urethra. This disease is the three most common diseases in the field of urology besides urinary tract infections and benign prostate enlargement. Kidney stones are the most common, with an estimated lifetime prevalence as high as $15 \%$. Bladder stones have significant morbidity but occur much less frequently than kidney stones. Many factors cause reduced urine flow and cause obstruction, one of which is urine static and decreased urine volume due to dehydration and inadequate fluid intake, this can increase the risk of nephrolithiasis. Low urine flow is a common abnormal symptom. In addition, various conditions that trigger nephrolithiasis such as the composition of various stones are the main factors in identifying the cause of nephrolithiasis. Aims of this article is to review risk factors and pathophysiology of nephrolithiasis.
\end{abstract}

Discussion: Symptoms associated with urinary tract stones depend on the location of the stone, the size of the stone, and any complications that have occurred. Usually, stones in the kidney calyx are asymptomatic. When the stone falls off and descends into the narrow ureter, it becomes symptomatic. Stones generally get stuck in the narrowest part of the ureter, such as the ureteropelvic junction, when the ureter crosses the iliac vasa, and the uretero-vesical junction.

The main symptom of ureteric stones is often an acute onset of pain in the back. This pain can be colicky or not. Colic pain occurs because the peristaltic activity of the smooth muscle of the calical system or ureter increases in an attempt to remove stones from the urinary tract. The increase in peristalsis causes the intraluminal pressure to increase so that there is stretching of the nerve terminals that provide a sensation of pain. The pain can radiate from the pelvis and to the ipsilateral groin. Other symptoms include nausea, vomiting and hematuria. Hematuria can occur macros or microscopy from urinalysis. Hematuria occurs as a result of trauma to the urinary tract mucosa caused by stones.

Conclusion: Nephrolithiasis is rock-forming salt reaches a urine concentration that exceeds the equilibrium point between the dissolved component and crystallization occurs. There are several risk factors that nephrolithiasis occurs due to various causes. Therapy and lifestyle changes are interventions that can change risk factors, but there are also risk factors that cannot be changed.

Keywords: neprolithiasis; pathophysiology; risk factors

\section{Introduction}

Nephrolithiasis is a urinary tract stone disease that can be found in the kidneys, ureters, bladder, and urethra. This disease is the three most common diseases in the field of urology besides urinary tract infections and benign prostate enlargement. Kidney stones are the most common, with an estimated lifetime prevalence as high as $15 \%$. Bladder stones have significant morbidity but occur much less frequently than kidney stones $[1,2]$.
Nephrolithiasis is a condition in which individual urinary tract stones are formed in the form of crystals that precipitate from urine. Nephrolithiasis is a collection of urinary tract stones, but in detail there are several mentions. The following is the term stone disease based on the location of the stone, among others:

1) Nephrolithiasis is called a stone in the kidney

2) Nephrolithiasis is called a stone in the ureter

3) Vesicolithiasis is referred to as a stone in the bladder / bladder stones 
4) Nephrolithiasis referred to as stones in the urethra [3, 4].

Nephrolithiasis can cause a variety of symptoms depending on the location of the stone, the level of infection and the presence or absence of urinary tract obstruction. Some clinical features that can appear in nephrolithiasis patients:

1) Pain in the kidneys can cause two types of pain, namely colicky and non-colic pain. Colic pain occurs due to stagnation of stones in the urinary tract resulting in resistance and irritability to the surrounding tissue.

2) Micturition disorders with obstruction in the urinary tract, the urine flow has decreased so that it is very difficult to spontaneously urinate.

3) Hematuria Stones trapped in the ureter (ureteric colic) often have a urge to urinate, but only a little urine comes out. This situation will cause friction caused by stones so that the urine that is excreted mixes with blood (hematuria).

4) Nausea and vomiting this condition is a side effect of the patient's discomfort because the pain is so intense that the patient experiences high stress and stimulates the secretion of $\mathrm{HCl}$ in the stomach.

5) Fever occurs because of germs that spread to other places.

6) Distention of bladder, accumulation of high urine that exceeds the ability of bladder will cause maximal vasodilation of the bladder. Therefore, a dam will be felt (distention) when the Vesica region is palpated $[5,6,7]$.

Many factors cause reduced urine flow and cause obstruction, one of which is urine static and decreased urine volume due to dehydration and inadequate fluid intake, this can increase the risk of nephrolithiasis. Low urine flow is a common abnormal symptom $[8,9]$. In addition, various conditions that trigger nephrolithiasis such as the composition of various stones are the main factors in identifying the cause of nephrolithiasis. Aims of this article is to review risk factors and pathophysiology of nephrolithiasis.

\section{Discussion}

Symptoms associated with urinary tract stones depend on the location of the stone, the size of the stone, and any complications that have occurred. Usually, stones in the kidney calyx are asymptomatic. When the stone falls off and descends into the narrow ureter, it becomes symptomatic. Stones generally get stuck in the narrowest part of the ureter, such as the uretero-pelvic junction, when the ureter crosses the iliac vasa, and the uretero-vesical junction [10, 11].

The main symptom of ureteric stones is often an acute onset of pain in the back. This pain can be colicky or not. Colic pain occurs because the peristaltic activity of the smooth muscle of the calical system or ureter increases in an attempt to remove stones from the urinary tract. The increase in peristalsis causes the intraluminal pressure to increase so that there is stretching of the nerve terminals that provide a sensation of pain. The pain can radiate from the pelvis and to the ipsilateral groin. Other symptoms include nausea, vomiting and hematuria. Hematuria can occur macros or microscopy from urinalysis. Hematuria occurs as a result of trauma to the urinary tract mucosa caused by stones $[12,13]$.

\section{Risk Factor of Nephrolithiasis}

Epidemiologically, there are several factors that facilitate the occurrence of urinary tract stones in a person. These factors include intrinsic factors, namely conditions originating from a person's body and extrinsic factors, namely influences originating from the surrounding environment $[14,15]$.

\section{Intrinsic factors include:}

1. Hereditary (descendants)
2. Age

Stones can form at any age, but most occur in adults between the ages of 30 and 60 .

\section{Gender}

Historically, men were affected more often than women, at a ratio of 2 or 3: 1 .

Although recent evidence suggests that the gender gap may be closing.

\section{Extrinsic factors include:}

1. Geography

The prevalence is higher in hot, dry, or dry climates such as mountains, deserts or tropical areas.

\section{Climate and temperature}

\section{Diet}

High fluid intake and low protein intake reduce the risk of stone formation. A diet high in purines, oxalates, and calcium makes it easier for stones to form.

4. Work

Exposure to heat, dehydration, workers who work a lot of sitting or lack of activity or sedentary life.

Risk Factors in general, nephrolithiasis occurs due to various causes, called risk factors. Therapy and lifestyle changes are interventions that can change risk factors, but there are also risk factors that cannot be changed.

1) Gender, patients with nephrolithiasis generally occur in $70-81 \%$ men compared to $47-60 \%$ women, one of the causes is an increase in testosterone levels and a decrease in estrogen levels in men in stone formation.

2) Age, nephrolithiasis occurs more frequently in adults than in old age, but when compared with the age of children, old age is more common (Portis \& Sundaram, 2001).

3) Family History, patients who have a family history of nephrolithiasis may help in the formation of urinary tract stones in patients $(25 \%)$ this may be due to the increased production of mucoproteins in the kidneys or bladder which can form crystals and form into stones or calculi [16].

4) Diet habits and obesity Intake of foods that are high in sodium, oxalate which can be found in tea, instant coffee, soft drinks, cocoa, strawberries, citrus fruits, and green vegetables, especially spinach, can cause stones.

5) Environmental factors, factors related to the environment such as geographic location and climate. Some areas show a higher incidence of nephrolithiasis than other areas.

6) Work Jobs that require work in a high temperature environment and limited or limited fluid intake can stimulate a lot of fluid loss and are the greatest risk in the stone formation process due to a decrease in the volume of urine.

7) Fluid intake is said to be insufficient if $<1$ liter / day, this lack of fluid intake is the main cause of nephrolithiasis, especially nephrolithiasis because this can lead to reduced urine flow / urine volume [17].

\section{Pathophysiology of nephrolithiasis}

When the rock-forming salt reaches a urine concentration that exceeds the equilibrium point between the dissolved component and the crystals, crystallization occurs. Although certain chemicals in the urine can delay 
stone formation, there are concentrations of rock-forming salts that cause crystallization to be inevitable. Factors that increase the likelihood of stone formation are decreased urine volume, an increase in the amount of rock-forming salt, or a decrease in the number of crystallization inhibitors [2].

The most common component is calcium stones, which are nearly $80 \%$ of all urinary tract stones. Calcium oxalate was found in nearly $60 \%$ of urinary tract stones, a mixture of calcium oxalate and hydroxyapatite about $20 \%$, uric acid and struvite about $7 \%$ of stones, and cystine stones only represented about $1 \%$ [18].

\section{Calcium Stone}

A number of pathophysiology contributes to the formation of calcium stones, namely hypercalciury, hyperoxalury, hyperuricosuria, hyperoxaluria and hypomagnesuria [19].

\section{Hypercalciuri}

Normally the kidneys filter about $270 \mathrm{mmol}$ of calcium per day and reabsorb about $4 \mathrm{mmol}$. It is called hypercalciuri if the calcium level in the urine is greater than $200 \mathrm{mg} / 24$ hours after adherence to a diet of 400 $\mathrm{mg}$ of calcium and $100 \mathrm{mg}$ of sodium for 1 week. Parks and Coe defined excretion greater than $4 \mathrm{mg} / \mathrm{kg}$ / day or more than $7 \mathrm{mmol} /$ day in men and $6 \mathrm{mmol} /$ day in women. There are 3 kinds of causes of hypercalcuri, including:

- Absorbtive hypercalcium: Increased absorption of calcium through urine.

- Renal hypercalcium: Impaired ability to reabsorb calcium through the renal tubules.

- resorptive hypercalcium: Increased bone calcium resorption, in primary hyperparathyroidism or in parathyroid tumors.

Hyperoxalury

Hyperkosaluri is urinary oxalate excretion that exceeds 40 grams / day. There are 3 kinds of causes of hyperoksaluri, including: • Hyperoxalury primers: Disruption in the biosynthetic pathway

- Enteric hyperoksauri: State of intestinal malabsorption associated with inflammatory bowel disease, celiac sprue, or bowel resection.

- Dietary hyperoksaluri: Excessive intake of high oxalate, such as tea, instant coffee, soft drinks, cocoa, strawberries, citrus, and green vegetables especially spinach.

\section{Hyperuricosuria}

Uric acid levels in the urine that exceed $600 \mathrm{mg} /$ day. Increased levels of monosodium urate in the urine, acting as a stone core / nidus for the formation of calcium oxalate through heterogeneous nucleation or epitaxial crystal growth. The most common cause of uric acid in the urine comes from foods that contain lots of purines and from endogenous metabolism[20].

\section{Hypocytraturia}

It is defined if the citrate level in the urine is less than $320 \mathrm{mg} /$ day. In the urine, citrate reacts with calcium to form calcium citrate, thus blocking the bonding of calcium with oxalate or phosphate. This is possible because calcium citrate bonds are more soluble than calcium oxalate. Therefore citrate acts as an inhibitor of calcium stone formation. Hypositratury can occur in renal tubular acidosis, malabsorption syndrome, or long-term use of thiazide diuretics.

\section{Hypomagnesuria}

Magnesium acts as an inhibitor for calcium stone formation. In the urine, magnesium reacts with oxalate to become magnesium oxalate, thus preventing calcium bonding with oxalate. The most common cause of hypomagnesuria is inflammatory bowel disease followed by impaired malabsorption [21].

\section{Uric Acid Stone}

Gout, myeloproliferative disease, patients receiving anticancer therapy, and those who use uricosuric drugs such as silfinpirazone, thiazide, and salicylates often suffer from uric acid stone disease. Overweight, drinking alcohol, and a diet high in protein have a greater chance of getting this disease [21].

Degradation of purines in the body through inosinic acid is converted into hypoxanthine. With the help of the xanthin oxidase enzyme, hypoxanthine is converted into xanthin which is finally converted into uric acid. Uric acid is excreted into the urine in the form of free uric acid and uric salts which are more directly bound to sodium to form sodium urate. Urate is relatively insoluble in the urine so that in certain circumstances it is easy to form uric acid crystals, and then to form uric acid stones.The factors that cause uric acid to form are urine that is too acidic, (urine $\mathrm{H}<6$ ), low urine volume (<2 liters / day) or dehydration, and hyperuricosuria or high uric acid levels [2,3]. 


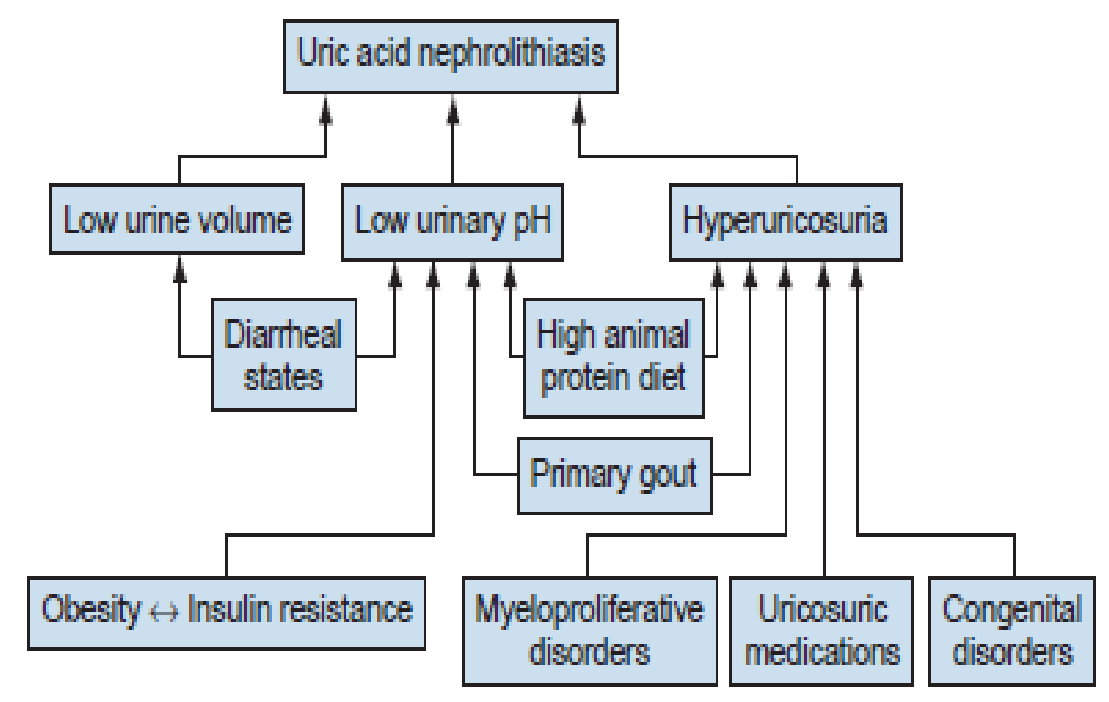

Figure 1: Pathophysiology and etiology of nephrolithiasis

\section{Struvit Stone}

Also called infection stones, because their formation is caused by a urinary tract infection. The germs that cause this are bacteria that break down urea or urea splitters which can produce urease enzymes and turn urine into an alkaline atmosphere through the hydrolysis of urea into ammonia, such as in the reaction $\left(\mathrm{NH}_{2}\right)_{2} \mathrm{CO}+\mathrm{H}_{2} \mathrm{O}$ into $2 \mathrm{NH}_{3}+\mathrm{CO}_{2}[24$, $25]$.

The alkaline atmosphere allows the magnesium, ammonium, phosphate, and kerbonate salts to form magnesium ammonium phosphate (MAP) and apatite carbonate stones. Because it consists of 3 cations, this type of stone is known as a triple-phosphate rock. Germs that break down urea are Proteus spp, Klebsiella, Serratia, Enterobacter, Pseudomonas, and Staphylococci [26, 27].

\section{Conclusion}

Nephrolithiasis is rock-forming salt reaches a urine concentration that exceeds the equilibrium point between the dissolved component and crystallization occurs. There are several risk factors that nephrolithiasis occurs due to various causes. Therapy and lifestyle changes are interventions that can change risk factors, but there are also risk factors that cannot be changed.

\section{References}

1. Basuki B. Purnomo. 2011. Dasar-dasar Urologi. Malang: Sagung Seto.

2. Netter F.H., Kelly C.R., Landman J. (2012) The Netter Collection of Medical Illustrations Urinary System, Volume 5, Second Edition. New York: Elsevier.

3. Wein A.J., Kavoussi L.R., Partin A.W., Peters, C.A. (2016) Campbell-Walsh Urology, Eleventh Edition. Philadelphia: Elsevier.

4. Scales CD, Smith AC, Hanley JM, Saigal CS. (2012) Urologic Diseases in America Project. Prevalence of kidney stones in the United States. Eur Urol. 62(1):160-165.

5. Chung MJ. (2017) Nephrolithiasis and nephrolithiasis. JAAPA. 30(9):49-50.

6. Caudarella R, Vescini F. (2009) Urinary citrate and renal stone disease: the preventive role of alkali citrate treatment. Arch Ital Urol Androl. 81(3):182-187.
7. Curhan GC, Willett WC, Rimm EB, Stampfer MJ. (1997) Family history and risk of kidney stones. J Am Soc Nephrol. 8(10):1568-1573.

8. Espino-Grosso PM, Canales BK. (2017) Kidney Stones After Bariatric Surgery: Risk Assessment and Mitigation. Bariatr Surg Pract Patient Care. 12(1):3-9.

9. Hesse AT, Tiselius H-G, Siener R, et al. (Eds). (2009) Urinary Stones, Diagnosis, Treatment and Prevention of Recurrence. 3rd edn. Basel, S. Karger AG.

10. Basiri A, Shakhssalim N, Khoshdel AR, et al. (2010) Familial relations and recurrence pattern in nephrolithiasis: new words about old subjects. Urol J. 7(2):81-86.

11. Taylor EN, Stampfer MJ, Curhan GC. (2005) Obesity, weight gain, and the risk of kidney stones. JAMA. 293(4):455-462.

12. Aune D, Mahamat-Saleh Y, Norat T, Riboli E. (2018) Body fatness, diabetes, physical activity and risk of kidney stones: a systematic review and meta-analysis of cohort studies. Eur $\mathbf{J}$ Epidemiol. 33(11):1033-1047.

13. Tiselius HG, Ackermann D, Alken P, et al. (2001) Working Party on Lithiasis, European Association of Urology. Guidelines on Nephrolithiasis. Eur Urol. 40(4):362-371.

14. Preminger GM, Tiselius HG, Assimos DG, et al. (2007) American Urological Association Education and Research, Inc; European Association of Urology. 2007 Guideline for the management of ureteral calculi. Eur Urol. 52(6):1610-1631.

15. Izzedine H, Lescure FX, Bonnet F. (2014) HIV medicationbased nephrolithiasis. Clin Kidney J. 7(2):121-126.

16. Parkhomenko E, De Fazio A, Tran T, Thai J, Blum K, Gupta M. (2017) A Multi-Institutional Study of Struvite Stones: Patterns of Infection and Colonization. J Endourol. 31(5):533537.

17. Preminger GM, Tiselius HG, Assimos DG, et al. (2007) EAU/AUA Nephrolithiasis Guideline Panel. Guidelines on nephrolithiasis. J Urol. 178(6):2418-2434.

18. Trinchieri A CG KS, Jun Wu K. (2003) Epidemiology. In: Stone Disease. C.P. Segura JW KS, Pak CY, Preminger GM, Tolley D., eds. Health Publications, Paris. 13-30.

19. Stamatelou KK, Francis ME, Jones CA, et al. (2003) Time trends in reported prevalence of kidney stones in the United States: 1976-1994. Kidney Int 63(5):1817-1823. 
20. Ma Q, Fang L, Su R, Ma L, Xie G, Cheng Y. (2018) Uric acid stones, clinical manifestations and therapeutic considerations. Postgrad Med J. 94(1114):458-462.

21. Eggermann T, Venghaus A, Zerres K. (2012) Cystinuria an inborn cause of nephrolithiasis. Orphanet J Rare Dis.

22. Khan SR, Pearle MS, Robertson WG, Gambaro G, Canales BK, Doizi S, Traxer O, Tiselius HG. (2016) Kidney stones. Nat Rev Dis Primers.

23. Maalouf NM, Cameron MA, Moe OW, Sakhaee K. (2004) Novel insights into the pathogenesis of uric acid nephrolithiasis. Curr Opin Nephrol Hypertens. 13(2):181-189.
24. Sarica K. (2006) Pediatric nephrolithiasis: etiology, specific pathogenesis and medical treatment. Urol Res. 34(2):96-101.

25. Shadman A, Bastani B. (2017) Kidney Calculi: Pathophysiology and as a Systemic Disorder. Iran J Kidney Dis. 11(3):180-191.

26. Semins MJ, Matlaga BR. (2014) Kidney stones during pregnancy. Nat Rev Urol. 11(3):163-168.

27. Brisbane W, Bailey MR, Sorensen MD. (2016) An overview of kidney stone imaging techniques. Nat Rev Urol. 13(11):654662. 